\title{
Carbohydrate and Torpor Duration in Hibernating Golden-Mantled Ground Squirrels (Citellus lateralis)
}

\author{
Mark L. Zimmerman \\ Division of Biological Sciences, University of Michigan, Ann Arbor, Michigan 48109, USA \\ Accepted January 16, 1982
}

Summary. Plasma glucose concentrations were increased in torpid Citellus lateralis to test the hypothesis that plasma glucose depletion stimulates periodic arousals from torpor during hibernation.

It was found that plasma glucose depletion is not the stimulus for arousal in C. lateralis (Figs. 1 and 2). Plasma glucose and hepatic and skeletal muscle glycogen remain stable during torpor in this species (Figs. 2-4), in marked contrast to the carbohydrate depletion reported for Citellus undulatus. The significance of the differences in carbohydrate status during torpor between $C$. lateralis and $C$. undulatus is discussed.

\section{Introduction}

Small mammals living in temperate climates commonly hibernate as a means of reducing their energy requirements during the winter when food is scarce. The major energy savings of hibernation are gained by entering torpor, in which the hibernator allows its body to cool to reduce its metabolic rate. But no animal is known to remain torpid continuously throughout hibernation. Torpor is interrupted at regular intervals by arousals, when the animal restores its normothermic body temperature for several hours before reentering torpor (Wang 1978). Over $80 \%$ of the total energy cost of hibernation is accounted for by the expense of rewarming from torpor and maintaining normothermia during arousals (Wang 1978). This high energy cost at a time when energy expenditures should be minimized suggests that arousals are necessary for the performance of some essential function.

The most prevalent view of the role of arousal in hibernation is that arousals are necessary for the restoration of kidney function to clear the body of metabolic wastes accumulated during torpor (Pengelley and Fisher 1961). There is evidence that the kidneys are nonfunctional during torpor due to inadequate perfusion by the blood (Deavers and Musacchia 1980). However, measurements of plasma urea and ammonia have failed to demonstrate an accumulation of these metabolites during torpor (Godin et al. 1967; Pengelley et al. 1971; Galster and Morrison 1975a).

An alternative explanation for arousal was advanced by Galster and Morrison (1970, 1975a) on the basis of measurements of plasma glucose and tissue glycogen in the arctic ground squirrel Citellus undulatus. Glycogen and plasma glucose are depleted during torpor and restored during arousal, without food intake, from endogenous glucose precursor, suggesting that arousals are necessary to restore carbohydrate reserves that are depleted during torpor. The correlation established between the rate of depletion of plasma glucose during torpor and torpor duration (Galster and Morrison 1970) further implies that plasma glucose depletion is actually the signal for arousal. In addition, the fact that nitrogenous wastes are accumulated and excreted only during arousals, when carbohydrate reserves are replenished, and not during torpor, when the reserves are depleted (Galster and Morrison 1975a), suggests a connection between Galster and Morrisons' hypothesis and the kidney hypothesis for arousal. In the absence of dietary intake the organism's carbohydrate requirement can only be satisfied by mobilizing glycogen reserves or by gluconeogenesis from protein (Felig 1979). Hibernators may avoid a toxic accumulation of nitrogenous wastes during torpor by inhibiting protein catabolism, with a resulting disruption of carbohydrate homeostasis.

An obvious prediction that can be made from the hypothesis that carbohydrate depletion triggers arousal from torpor is that torpor should be prolonged if the rate of depletion of carbohydrate is 
artificially reduced. The present paper describes an attempt to test this prediction using triundecanoin feeding to slow the anticipated depletion of carbohydrate during torpor. Triundecanoin is the triglyceride of the $\mathrm{C}_{11}$ fatty acid undecanoate, which is glucogenic because its terminal beta-oxidation produces one propionyl-CoA for each fatty acid oxidized. PropionylCoA enters the glucogenic pathway by way of propionyl-CoA carboxylase, which is the route for glucose precursor derived from the amino acids valine and isoleucine (Snell 1980). When present in the diet, the undecanoate moiety of triundecanoin is incorporated directly into the depot fat (Campbell and Hashim 1969). Rats show much slower rates of carbohydrate depletion during starvation after eating diets containing odd-numbered fat than after diets containing natural, even-numbered fat (VanItallie et al. 1977; Anderson and Volpenhein 1979).

\section{Materials and Methods}

Golden-mantled, Citellus lateralis, rather than arctic ground squirrels were used because of logistic considerations. A previous study had shown that plasma glucose remains stable during torpor in golden-mantled ground squirrels (Twente and Twente 1967a), but the sampling technique used by Twente and Twente differed importantly from that used by Galster and Morrison (cardiac puncture of unanesthetized animals as opposed to decapitation, respectively), food was available to the animals during arousals, and the quantity of tissue glycogen present during torpor was not measured.

Ground squirrels were trapped in late June, 1980, on the Elk River in Routt National Forest, Colorado, at about 2,500 m elevation. The animals were transported to Ann Arbor, Michigan, where they were maintained in the laboratory.

In early October the animals were starved until they returned to their field body weights or for 10 days (whichever was soonest), and were then fed diets containing either triundecanoin or natural fat. The weight gains on the experimental diet ranged from 10 to $80 \%$ of the body weights at the start of refeeding and did not differ from the weight gains on the control diet.

On November 1 the animals were placed in a darkened cold room at $4-6{ }^{\circ} \mathrm{C}$. All food was removed after three weeks in the cold. To monitor arousal frequency (Twente and Twente 1965), constantan-copper thermocouples protected by an insulated strip of sheet aluminum were nailed to the bottoms of enclosed, wooden nest boxes with $4 \mathrm{~cm}$ diameter entrance holes. The thermocouple temperatures were recorded continuously using Honeywell Electronik 16 and 112 recorders placed outside the cold room. Arousals caused a $15-20^{\circ} \mathrm{C}$ elevation of the nest box temperatures, so that the times of arousal and entrance into torpor were easily determined without disturbing the animals

In late January and early February, 1981, the animals were killed early or late during torpor, i.e. after they had been torpid for either approximately $5 \%$ or $90 \%$ of the duration of the previous, completed torpor bout. The animals were weighed, decapitated, and bled into iced, heparinized centrifuge tubes. The blood was spun in a refrigerated centrifuge, and the plasma stored at $-20^{\circ} \mathrm{C}$. The liver, heart, triceps of the forelegs, and semitendinosus and adjacent muscles of the thighs were removed in that order, weighed, and frozen in a dry ice-ethanol bath as rapidly as possible, then stored at $-20^{\circ} \mathrm{C}$.
Plasma glucose was determined by the glucose oxidase method (Sigma Technical Bulletin no. 635), glycogen by the amyloglucosidase method of Keppler and Decker (1974), and plasma urea by the coupled urease-glutamic dehydrogenase method (Sigma Technical Bulletin no. 65-UV). All assay reagents were purchased from Sigma. The Mann-Whitney $U$-test was used to determine the significance of differences between sample groups (Sokal and Rohlf 1969). Null hypotheses were rejected at the 0.05 level.

Triundecanoin is not commercially available. The synthesis technique employed follows generally that of Campbell and Hashim (1969). A $250-500 \mathrm{ml}$ volume of undecylenic acid (U.S. Biochemical Corp.) was dissolved in an equal volume of $100 \%$ ethanol for increased fluidity and then hydrogenated to undecanoate at room temperature under a 45 psi hydrogen atmosphere with $2.5 \%$ by volume Raney Nickel catalyst (Aldrich Chemical Corp.). Hydrogen uptake was promoted by continuously shaking the reaction mixture. The mixture was exposed to a known (4.51) volume of hydrogen gas, so that the extent of hydrogenation could be monitored by following the decline in hydrogen pressure over the reaction mixture. In all instances the hydrogen uptake upon completion of the reaction was within $2 \%$ of the predicted uptake. When hydrogenation was complete the catalyst was removed by repeated filtration through a Büchner funnel, and the ethanol by warming with stirring under an aspirator vacuum. Esterification was carried out under a nitrogen atmosphere with heating in a $200^{\circ} \mathrm{C}$ sand bath. The reaction mixture contained undecanoate in a slight excess ( $5 \%$ by weight) over a $3: 1$ undecanoate: glycerol molar ratio to promote complete glycerol esterification, and $5 \%$ by weight $p$ toluenesulfonic acid monohydrate catalyst (Aldrich Chemical Corp.). The mixture was stirred by continuous bubbling of nitrogen. An open system was used in order to remove the water produced by the formation of ester linkages, promoting full glycerol esterification (Mattson and Volpenhein 1962). An excess of glycerol was added after approximately $2 \mathrm{~h}$, when the reaction was judged to be nearly complete on the basis of a reduced evolution of water. After about one additional hour, the mixture was cooled, and the catalyst and excess glycerol removed by five washings in equal volumes of distilled water. No attempt was made to determine the homogeneity of the preparation, as the reaction conditions were too mild to alter the fatty acid chain length (Mattson and Volpenhein 1962). The preparation was filtered and mixed with sunflower oil to produce a $65 \%$ by weight triundecanoin mixture. This mixture was added to pulverized Purina rabbit chow for a diet containing $15 \%$ fat mixture. The control diet contained an equal weight of pure sunflower oil.

\section{Results}

The animals showed a typical pattern of hibernating behavior (Morrison and Galster 1975; Twente and Twente 1967 b), entering hibernation with relatively short torpor bouts that successively increased in duration, tending to stabilize at between 200 and $300 \mathrm{~h}$ duration (Fig. 1). Torpor duration was unaffected by triundecanoin feeding (Fig. 1). The duration of the last uninterrupted torpor bout did not differ between the two dietary groups. The mean and standard deviation of the last torpor bout was $249 \pm 26 \mathrm{~h}$ for animals fed the experimental diet and $264 \pm 33 \mathrm{~h}$ for animals fed the control diet.

Squirrels fed the control diet showed stable plasma glucose during torpor (Fig. 2). Animals killed in early torpor had plasma glucose concentrations of 

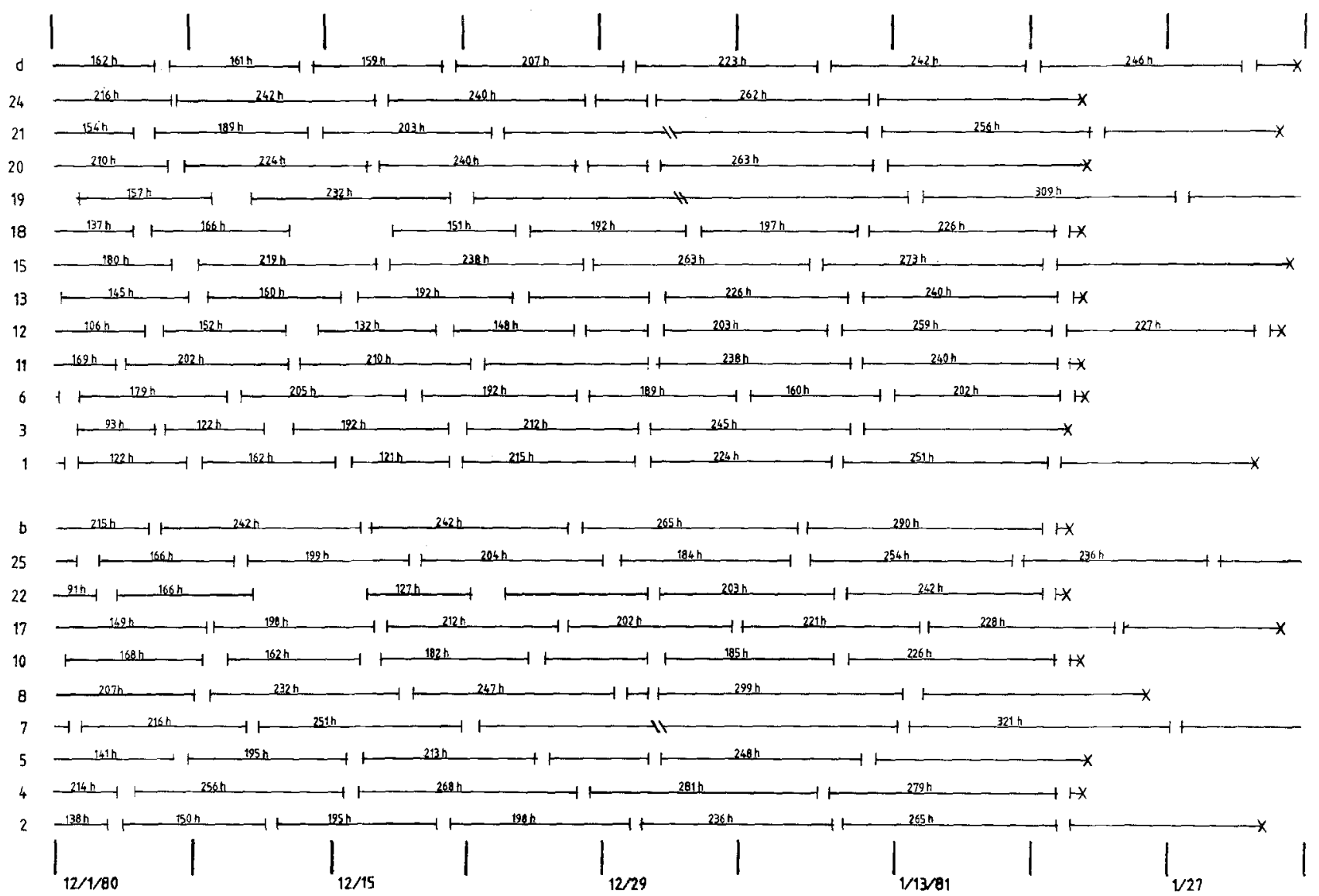

Fig. 1. Torpor duration in golden-mantled ground squirrels hibernating at 4-6 ${ }^{\circ} \mathrm{C}$. Solid lines indicate time torpid, gaps indicate arousals, and crosses indicate when the animals were killed. Yertical slashes designate weekly intervals. Animals 1 through d were fed triundecanoin, 2 through $b$ were fed the control diet. The durations of the last torpor bout completed by each animal did not differ between the two dietary groups (Mann-Whitney $U ; P>0.05$ ). Power cutoff on December 31 caused the cold room to warm, stimulating many animals to arouse

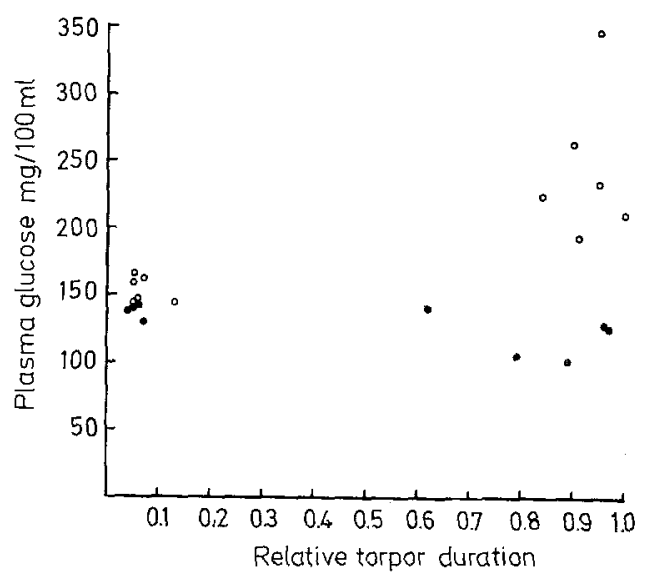

Fig. 2. Plasma glucose concentrations in torpid golden-mantled ground squirrels. Open circles designate triundecanoin-fed animals, closed circles normal-fed animals. Relative torpor duration is the time torpid when killed divided by the duration of the previous, completed torpor bout (Twente and Twente 1967a). Plasma glucose concentration was higher (Mann-Whitney $U ; P<0.001$ ) in triundecanoin-fed animals killed in late torpor compared to normal-fed animals or triundecanoin-fed animals killed in early torpor. Normal-fed animals killed in late torpor did not differ from normal-fed animals killed in early torpor (Mann-Whitney $U ; P>0.05$ )
$138 \pm 5.9 \mathrm{mg} / 100 \mathrm{ml}$, while animals killed in late torpor had $120.6 \pm 16.6 \mathrm{mg} / 100 \mathrm{ml}$ and did not differ from early-killed animals. Animals fed the experimental diet showed higher plasma glucose concentrations compared to control animals when they were killed during late torpor $(245.7 \pm 54.8 \mathrm{mg} / 100 \mathrm{ml} ; P<0.001)$ but not when killed during early torpor $(153.8 \pm 9.6 \mathrm{mg} / 100 \mathrm{ml})$.

Liver glycogen (Fig. 3) apparently remained stable throughout torpor in control $(8.3 \pm 2.9 \mathrm{mg} / \mathrm{g}$ wet weight in early-killed; $6.7 \pm 1.4$ in late-killed) as well as in triundecanoin-fed animals $(12.6 \pm 3.6$ in earlykilled; $10.8 \pm 4.9$ in late-killed). Triundecanoin-fed animals had somewhat higher liver glycogen contents compared to normal-fed animals ( $11.7 \pm 4.2$ triundecanoin-fed and $7.4 \pm 2.2$ normal-fed; $P<0.025$ ). Thigh (Fig. 4) and foreleg (not shown) glycogen remained stable throughout torpor, and the triundecanoin-fed animals did not differ from the normal-fed. Triundecanoin-fed animals (combined early- and latekilled) had $9.0 \pm 1.0 \mathrm{mg} / \mathrm{g}$ wet weight glycogen in thigh and $9.6 \pm 1.1 \mathrm{mg} / \mathrm{g}$ foreleg muscle; normal-fed ani- 


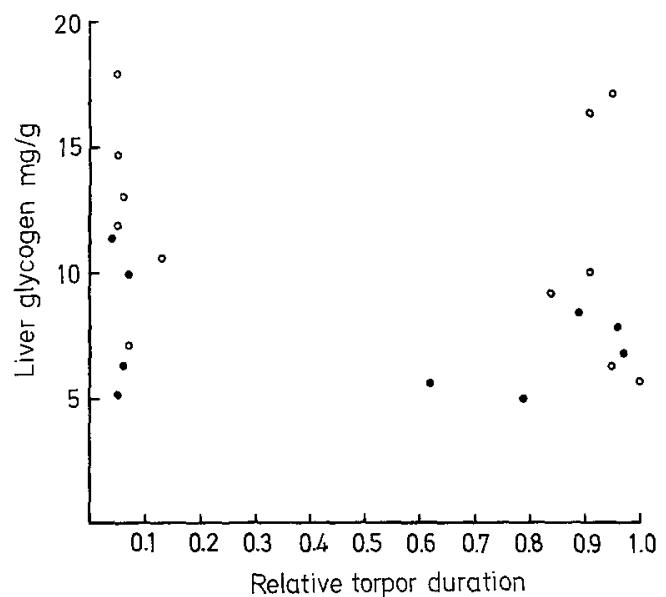

Fig. 3. Liver glycogen content (mg/g wet weight) in torpid goldenmantled ground squirrels. Designations same as in Fig. 2. Liver glycogen content was higher (Mann-Whitney $U ; P<0.025$ ) in triundecanoin-fed than in normal-fed animals. Late-killed triundecanoin-fed animals did not differ from early-killed triundecanoin-fed animals; late-killed normal-fed animals did not differ from earlykilled normal-fed animals (Mann-Whitney $U ; P>0.05$ )

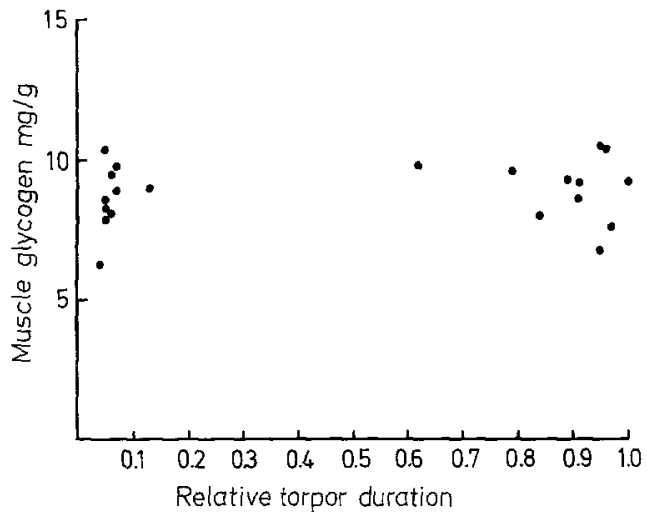

Fig. 4. Skeletal muscle glycogen in torpid golden-mantled ground squirrels. Samples from semitendinosus and adjacent muscles of the thigh. Triundecanoin- and normal-fed animals did not differ (Mann-Whitney $U ; P>0.05$ ) and were pooled. Animals killed in late torpor did not differ from animals killed in early torpor (MannWhitney $U ; P>0.05$ )

mals had $8.6 \pm 1.2 \mathrm{mg} / \mathrm{g}$ thigh and $8.4 \pm 1.7 \mathrm{mg} / \mathrm{g}$ foreleg. Animals killed early in torpor (combined triundecanoin- and normal-fed) showed $8.7 \pm 1.1 \mathrm{mg} / \mathrm{g}$ thigh and $8.9 \pm 1.8 \mathrm{mg} / \mathrm{g}$ foreleg glycogen; late-killed animals had $9.0 \pm 1.1$ thigh and $9.3 \pm 1.1 \mathrm{mg} / \mathrm{g}$ foreleg glycogen. Values for cardiac muscle glycogen did not differ between diets and remained unchanged during torpor $(4.7 \pm 0.9 \mathrm{mg} / \mathrm{g}$ wet weight in early-killed and $5.6 \pm 0.8 \mathrm{mg} / \mathrm{g}$ in late-killed). Plasma urea concentrations likewise did not differ between diets and remained unchanged during torpor $(136 \pm 36 \mathrm{mg}$ urea $\mathrm{N} /$ liter in early-killed animals and $171 \pm 78 \mathrm{mg} / \mathrm{l}$ in late-killed; Fig. 5).

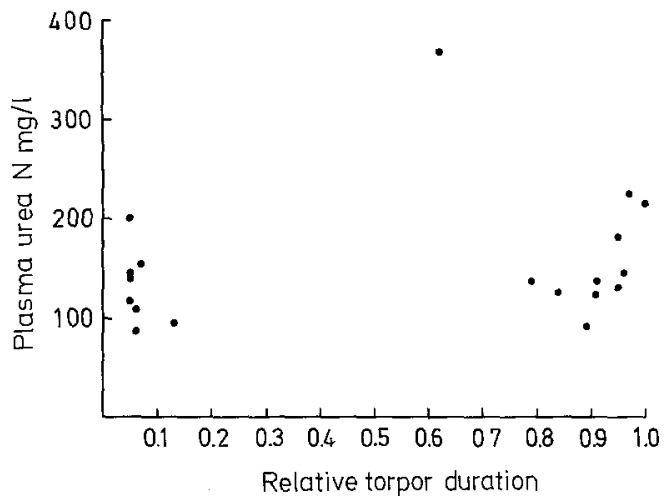

Fig. 5. Plasma urea concentrations in torpid golden-mantled ground squirrels. Triundecanoin- and normal-fed animals did not differ (Mann-Whitney $U ; P>0.05$ ) and were pooled. Animals killed in late torpor did not differ from animals killed in early torpor (Mann-Whitney $U ; P>0.05$ )

\section{Discussion}

Golden-mantled ground squirrels do not experience an impaired carbohydrate homeostasis during torpor, as demonstrated by the stability of plasma glucose (Fig. 2; Twente and Twente 1967a) and tissue glycogen (Figs. 3 and 4). These results, as well as the lack of an effect upon arousal frequency by an increased plasma glucose and liver glycogen (Figs. 1-3), negate the hypothesis that carbohydrate depletion causes periodic arousals from torpor. But the question of the relationship between carbohydrate metabolism and arousal remains open for $C$. undulatus, in which carbohydrate homeostasis is clearly disrupted during torpor (Galster and Morrison 1970, 1975a). It is unfortunate that there are few comparative data about the integrity of carbohydrate homeostasis during torpor in hibernators. With the exceptions of $C$. lateralis and C. undulatus, all published data for carbohydrate levels in hibernating Citellus are from animals sampled without reference to torpor duration and thus provide no information about the integrity of carbohydrate homeostasis during torpor. Certain nonrodent hibernators show a decreased plasma glucose during torpor (Sarajas 1967; Dodgen and Blood 1956), but the plasma glucose in these species appears to be dependent on body temperature rather than torpor duration.

The marked differences between $C$. undulatus and C. lateralis in the patterns of change in carbohydrate during torpor are intriguing. When hibernating in the laboratory without food the two species enter torpor with identical plasma glucose and tissue glycogen concentrations, but glucose and glycogen decline with torpor duration in C. undulatus while remaining stable in C. lateralis (Galster and Morrison 1970; Figs. 2-4). Glycogen reserves are depleted during fasting when the organism's rate of glucose consumption 
exceeds the rate of glucose synthesis. The stability of the glycogen reserves in $C$. lateralis is a reflection of the equal rates of glucose consumption and synthesis during torpor in this species, while C. undulatus, when torpid under identical conditions, evidently consumes glucose at a rate that exceeds the rate of glucose synthesis. The magnitude of these differences in carbohydrate metabolism can be demonstrated by estimating the energy yield of the glycogen mobilized during torpor in the arctic ground squirrel. The $924 \mathrm{mg}$ glucose mobilized from tissue glycogen during a single torpor bout account for $50 \%$ of the total oxygen consumed during torpor at $5{ }^{\circ} \mathrm{C}$ (Galster and Morrison 1975a).

Regression coefficients for glycogen depletion in the arctic ground squirrel are $5.16 \mathrm{mg}$ glycogen $/ \mathrm{g}$ skeletal muscle $\cdot$ torpor bout and $9.61 \mathrm{mg}$ glycogen/g liver torpor bout (coefficients calculated from Fig. 4 of Galster and Morrison, 1970; the probability that the coefficients equal zero is less than 0.005). Assuming that the skeletal muscle constitutes $50 \%$ and the liver $5 \%$ of the body weight of a $300 \mathrm{~g}$ squirrel (Galster and Morrison 1975a), glycogen contributes $924 \mathrm{mg}$ glucose, which amounts to $50 \%$ of the total oxygen consumed in 11 days of torpor (Galster and Morrison $1975 \mathrm{a}$ ) if $0.84 \mathrm{ml} \mathrm{O}_{2}$ are consumed per $\mathrm{mg}$ glucose oxidized (Schmidt-Nielsen 1979). The assumption that mobilized glycogen is terminally oxidized is based on the absence of lactate accumulation during torpor (Galster and Morrison 1975a).

Since torpid golden-mantled ground squirrels do not mobilize glycogen (Figs. 3 and 4), an equivalent portion of their energy requirement must be provided by glucose synthesized during torpor or, alternatively, by noncarbohydrate fuels.

It is unlikely that torpid golden-mantled ground squirrels maintain stable carbohydrate levels by maintaining a higher rate of glucose synthesis than do torpid arctic ground squirrels. The only precursors for the net synthesis of glucose in mammals are glycerol and protein (Felig 1979). The rate at which glycerol is made available for gluconeogenesis is limited by the organism's consumption of fatty acid. The increase in metabolic rate required in order to release glycerol at a rate sufficient to match the rate of glycogen depletion in C. undulatus can be estimated by assuming that $0.1 \mathrm{mg}$ glycerol is released per $1.0 \mathrm{mg}$ fat mobilized (Owen et al. 1969), $1.0 \mathrm{mg}$ glycerol provides $1.0 \mathrm{mg}$ glucose, $2 \mathrm{ml} \mathrm{O}_{2}$ are consumed per $1.0 \mathrm{mg}$ fat oxidized (Schmidt-Nielsen 1979), and that the glycogen depletion rate is $924 \mathrm{mg} / 300 \mathrm{mg}$ animal.11 days (see above). The arctic ground squirrel would have to maintain a metabolic rate of $0.2 \mathrm{ml}$ $\mathrm{O}_{2} / \mathrm{g} \cdot \mathrm{h}$ with fat oxidation, a nearly normothermic rate, in order to prevent glycogen depletion with gluconeogenesis from glycerol.

The lack of change in plasma urea (Fig. 5; Galster and Morrison 1975a) and total nonprotein nitrogen (Pengelley et al. 1971) during torpor argues against an appreciable rate of glucose synthesis from protein in either $C$. lateralis or $C$. undulatus. If the kidneys are nonfunctional (Deavers and Musacchia 1980), a significant contribution of protein to glucose homeostasis would result in an accumulation of nonprotein nitrogen during torpor. Assuming that one gram of nitrogen from catabolized protein yields $3.65 \mathrm{~g}$ glucose (Garber et al. 1974) and that the exchangeable body water constitutes $80 \%$ of the body weight (Katz and Dunn 1967), glucose synthesis from protein equivalent to the quantity of glycogen depleted in a $300 \mathrm{~g}$ arctic ground squirrel during a single torpor bout would result in the production of $250 \mathrm{mg} \mathrm{N}$. If this quantity of nitrogen were synthesized into urea and dispersed equally throughout the body water it would produce a urea concentration of about $1 \mathrm{~g}$ urea $\mathrm{N} /$ liter, or a five-fold increase over the $C$. undulatus plasma urea concentration in early torpor (Galster and Morrison 1975a). The constancy of urea nitrogen that is actually observed in both $C$. undulatus and C. lateralis strongly suggests that protein contributes little or no glucose precursor during torpor in either species.

Reincorporation of urea nitrogen into protein cannot explain the constancy of plasma urea during torpor. Hypotheses that nitrogen recycling plays an important role in hibernation metabolism (Nelson 1980; Riedesel and Steffen 1980) beyond the normal, appreciable recycling that occurs due to the presence of urease in the gut flora (Long et al. 1978; Richards 1972) overlook the fact that no polypeptide chain can be synthesized without the essential amino acids or else their keto analogues, the only source of which is dietary intake (Lehninger 1978; Sapir et al. 1974).

It must be concluded that the different patterns of change in glycogen content during torpor are due to differences in rates of glucose consumption. These differences cannot be attributed to differences in overall metabolic rates. Both $C$. undulatus and $C$. lateralis allow their bodies to thermally equilibrate with their surroundings when torpid at $5^{\circ} \mathrm{C}$ (Galster and Morrison 1975a; Twente and Twente 1965). Since lean arctic ground squirrels are at least twice as large as golden-mantled ground squirrels (Galster and Morrison 1975b; and unpublished), arctic ground squirrels ought to have a $20 \%$ lower weight-specific metabolic rate during torpor, based on the -0.25 exponent for weight-specific metabolic rate as a function of body mass (Schmidt-Nielsen 1979). If glycogen-derived glucose made a proportionately equal contribution to the oxygen consumption of both species, golden-mantled ground squirrels would show a faster rate of glycogen depletion than do arctic ground squirrels.

Arctic ground squirrels must have a greater relative dependence on glucose for their fuel requirements during torpor. This greater glucose dependence could 
hardly be a random species difference, since Citellus sp. are not known to store food for consumption during hibernation (Mrosovsky 1978; Bronson 1977), and glucose utilization should be minimized during prolonged starvation in order to spare tissue protein (Felig 1979). Furthermore, if a relation between arousal frequency and carbohydrate depletion could be unequivocably demonstrated in $C$. undulatus, then the apparent energetic cost of carbohydrate depletion would provide strong evidence for the existence of a carbohydrate requirement during torpor peculiar to $C$. undulatus that can only be satisfied by glycogen mobilization. Perhaps the greater requirement for carbohydrate demonstrated by $C$. undulatus in the laboratory is related to the unique conditions of hibernation that this animal faces in the wild. C. undulatus is the only mammal that hibernates in permafrost regions (Remmert 1980), and it must anticipate subzero hibernaculum temperatures for considerable lengths of time during hibernation (Mayer 1953; Williams and Rausch 1973). In contrast, subarctic hibernators can construct their hibernaculae below the frost line (Wang 1978). Ambient temperatures below about $2{ }^{\circ} \mathrm{C}$ elicit a thermogenic response in Citellus (Heller and Colliver 1974). Glucose consumption is required to sustain activity (Wahren 1979) and thermogenesis (Cannon et al. 1978), possibly because glucose consumption is necessary to sustain the levels of Krebs cycle intermediates (Cannon et al. 1978; M. Yacoe, personal communication). It is tempting to speculate that torpid arctic ground squirrels consume greater quantities of glucose in order to maintain a thermogenic capacity in the event of freezing hibernaculum temperatures.

Finally, the pattern of change in plasma glucose in the triundecanoin-fed squirrels (Fig. 2) deserves comment. Animals killed early in torpor showed normal plasma glucose; whereas animals killed late in torpor were without exception strongly hyperglycemic. The triundecanoin-fed squirrels developed hyperglycemia in the course of torpor, but returned their plasma glucose to normal levels during arousals prior to reentering torpor. Both torpid and aroused triundecanoin-fed animals must have obtained extra glucose precursor at a rate determined by their rate of fat mobilization and oxidation. That the animals allowed their plasma glucose to rise only during torpor indicates a lack of an insulin response to rising plasma glucose during torpor and supports ideas of impaired endocrine control during torpor (see Hudson and Wang 1978).

Acknowledgements. Byron A. Doneen and William R. Dawson provided laboratory space and equipment. Thanks to Marshall E. Yacoe for many hours of fruitful discussion, and to Bryon A. Doneen and Vincent W. Hylka for reviewing the manuscript. Rollin Gruschow provided valuable advice in animal maintenance.

\section{References}

Anderson RL, Volpenhein RA (1979) Carcass deposition of dietary long-chain odd carbon fatty acids by rats and their effect on plasma glucose and ketone bodies during starvation. J Nutr $109: 1810-1814$

Bronson MT (1977) Altitudinal variation in the annual cycle and life history of the golden-mantled ground squirrel (Spermophilus lateralis). PhD dissertation, University of California, Berkeley, p 64

Campbell R.G, Hashim SA (1969) Deposition in adipose tissue and transport of odd-numbered fatty acids. Am J Physiol 217:1614-1619

Cannon B, Nedergaard J, Romert L, Sundin U, Svartengren J (1978) The biochemical mechanism of thermogenesis in brown adipose tissue. In: Wang LCH, Hudson JW (eds) Strategies in cold: natural torpidity and thermogenesis. Academic Press, New York San Francisco London, pp 567-594

Deavers DR, Musacchia WJ (1980) Water metabolism and renal function during hibernation and hypothermia. Fed Proc 39:2969-2973

Dodgen CL, Blood FR (1956) Energy sources in the bat. Am J Physiol 187:151-154

Felig P (1979) Starvation. In: DeGroot LJ (ed) Endocrinology, vol 3. Grune and Stratton, New York San Francisco London, pp 1927-1940

Galster WA, Morrison PR (1970) Cyclic changes in carbohydrate concentrations during hibernation in the aretic ground squirrel. Am J Physiol 218:1228-1232

Galster WA, Morrison PR (1975a) Gluconeogenesis in arctic ground squirrels between periods of hibernation. Am J Physiol $228: 325-330$

Galster WA, Morrison PR (1975b) Seasonal changes in body composition of the arctic ground squirrel, Citellus undulatus. Can J Zool 54:74-78

Garber AJ, Menzel PH, Boden G, Owen OE (1974) Hepatic ketogenesis and gluconeogenesis in humans. $J$ Clin Invest $54: 981-989$

Godin Y, Mark J, Kayser Ch, Mandel P (1967) Ammonia and urea in the brain of garden dormice during hibernation. J Neurochem $14: 142-144$

Heller HC, Colliver GW (1974) CNS regulation of body temperature during hibernation. Am J Physiol 227:583-589

Hudson JW, Wang LCH (1979) Hibernation: endocrinologic aspects. Ann Rev Physiol 41:287-304

Katz J, Dunn A (1967) Glucose-2-T as a tracer for glucose metabolism. Biochemistry $6: 1-5$

Keppler D, Decker K (1974) Glycogen. In: Bergmeyer HU (ed) Methods of enzymatic analysis, vol 3. Academic Press, New York San Francisco London, pp 1127-1131

Lehninger AL (1978) Biochemistry, 2nd ed. Worth Publishers, New York

Long CL, Jeevanandam M, Kinney JM (1978) Metabolism and recycling of urea in man. Am J Clin Nutr 31:1367-1382

Mattson FH, Volpenhein RA (1962) Synthesis and properties of glycerides. J Lipid Res 3:281-296

Mayer WV (1953) The protective value of the burrow system to the hibernating arctic ground squirrel, Sphermophilus undulatus. Anat Rec 122:437-438

Morrison PR, Galster WA (1975) Patterns of hibernation in the arctic ground squirrel. Can J Zool 53:1345-1355

Mrosovsky N (1978) Circannual cycles in hibernators. In: Wang LCH, Hudson JW (eds) Strategies in cold: natural torpidity and thermogenesis. Academic Press, New York San Francisco London, pp 21--66

Nelson RA (1980) Protein and fat metabolism in hibernating bears. Fed Proc 39:2955-2958

Owen OE, Felig P, Morgan AP, Wahren J, Cahill GF (1969) 
Liver and kidney metabolism during prolonged starvation. J Clin Invest 48:574-583

Pengelley ET, Fisher $\mathrm{KG}$ (1961) Rhythmical arousal from hibernation in the golden-mantled ground squirrel. Can $J$ Zool 39:105-120

Pengelley ET, Asmundson SJ, Uhlman C (1971) Homeostasis during hibernation in the golden-mantled ground squirrel, Citellus lateralis. Comp Biochem. Physiol [A] 38:645-653

Remmert H (1980) Arctic animal ecology. Springer, Berlin Heidelberg New York, p 55

Richards P (1972) Nutritional potential of nitrogen recycling in man. Am J Clin Nutr 25:615-625

Riedesel ML, Steffen JM (1980) Protein metabolism and urea recycling in rodent hibernators. Fed Proc 39:2959-2963

Sapir DG, Owen OE, Pozefsky T, Walser M (1974) Nitrogen sparing induced by a mixture of essential amino acids given chiefly as their keto-analogues during prolonged starvation in obese subjects. J Clin Invest 54:974-980

Sarajas HSS (1967) Blood glucose studies in permanently cannulated hedgehogs during a bout of hibernation. Ann Acad Sci Fenn [Biol] 120:4-11

Schmidt-Nielsen K (1979) Animal physiology : adaptation and environment. Cambridge University Press, Cambridge London New York Melbourne

Snell K (1980) Muscle alanine synthesis and hepatic gluconeogenesis. Biochem Soc Trans 8:205-213
Sokal RR, Rohlf FJ (1969) Biometry. Freeman, San Francisco

Twente JW, Twente JA (1965) Effects of core temperature upon duration of hibernation of Citellus lateralis. J Appl Physiol $20: 411-416$

Twente JW, Twente JA (1967a) Concentrations of D-glucose in the blood of Citellus lateralis after known intervals of hibernating periods. J Mammal 48:381-386

Twente JW, Twente JA (1967b) Seasonal variation in the hibernating behavior of Citellus lateralis. In: Fisher KC, Dawe AR, Lyman CP, Schönbaum E, South FE (eds) Mammalian hibernation. III. American Elsevier, New York, pp 47-63

VanItallie TB, Smith NS, Quatermain D (1967) Short-term and long-term components in the regulation of food intake: evidence for a modulatory role of carbohydrate status. Am J Clin Nutr 30:742-757

Wahren J (1979) Metabolic adaptation to physical exercise in man. In: DeGroot LJ (ed) Endocrinology, vol 3. Grune and Stratton, New York San Francisco London, pp 1911-1926

Wang LCH (1978) Energetic and field aspects of mammalian torpor: the Richardson's ground squirrel. In: Wang LCH, Hudson JW (eds) Strategies in cold: natural torpidity and thermogenesis. Academic Press, New York San Francisco London, pp 109 147

Williams DD, Rausch RL (1973) Seasonal carbon dioxide and oxygen concentrations in the dens of hibernating mammals (Sciuridae). Comp Biochem Physiol [A] 44:1227-1235 